\title{
Digital Image Processing Assessment of the Differential in vitro Antiangiogenic Effects of Dimeric and Monomeric Beta2-Glycoprotein I
}

Camila Machado ${ }^{1}$, Miriela Escobedo Nicot ${ }^{2}$, Carolina Nigro Stella ${ }^{1}$, Sara Vaz ${ }^{1}$, Cassia Prado ${ }^{1}$, Durvanei Augusto Maria ${ }^{3}$, Francisco Palacios Fernandez $^{4}$ and Ligia Ferreira Gomes ${ }^{1^{*}}$

${ }^{1}$ Department of Clinical and Toxicological Analysis, Faculty of Pharmaceutical Sciences, University of São Paulo, Sao Paulo, Brazil

${ }^{2}$ Computer Sciences Department, Mathematical Computer Faculty, University of Oriente, Santiago de Cuba, Cuba

${ }^{3}$ Biochemical and Biophysical Laboratory, Butantan Institute, Sao Paulo, Brazil

${ }^{4}$ Physics Department, Natural Sciences Faculty, University of Oriente, Santiago de Cuba, Cuba

\begin{abstract}
The $\beta_{2}$-glycoprotein I ( $\left.\beta_{2} \mathrm{GPI}\right)$ is an endothelial cell ligand, accessible for systemic, autocrine and paracrine signaling. In vivo, $\beta_{2} \mathrm{GPI}$ is immobilized by binding, mainly to the endothelial cell membrane heparan sulfate but also to anionic phospholipids, and functional receptors. The $\beta_{2}$ GPI was attributed antiangiogenic properties both in vitro and in vivo. This work was designed to evaluate the antiangiogenic effects of native, monomeric, and dimeric $\beta_{2}$ GPI. Monomeric as well as dimeric forms were purified from human plasma, and the native protein was obtained as a balanced mixture of both components present in human plasma. The proliferation, migration, and differentiation of Human Umbilical Vascular Endothelial Cells (HUVEC) were considered in an in vitro angiogenesis model based on tridimensional cultures and quantitative digital image processing techniques. The early events of the in vitro HUVEC growth and differentiation in the tridimensional cultures microenvironment were addressed by the morphological analysis. The morphological aspects were correlated to the cell growth, oxidative balance outcome and mitochondrial toxicity assays, leading to the evidence that non-confluent HUVEC cultures temporarily stop growing in the presence of the native protein, but remain competent to proliferate. The $\beta_{2}$ GPI monomer allowed the in vitro differentiation of the HUVECs into typical trabeculæ and incomplete capillary-like tubes, along with lowering the available proliferation fraction. In opposition, the dimer rich purification fraction exposure halted cell elongation and migration, and prevented the organization of the tubular structures in tridimensional cultures, maintaining cell growth. The morphological approach was useful to attribute to $\beta_{2}$ GPI dimerization the cell migration inhibition modulation, which potentially leads to overcome the diminished sprouting antiangiogenic effect of the monomer fraction of the native protein.
\end{abstract}

Keywords: $\quad \beta_{2}$-Glycoprotein I; Angiogenesis; Digital image processing; Tridimesional cell cultures; HUVEC

\section{Introduction}

$\beta_{2}$-Glycoprotein I ( $\left.\beta_{2} \mathrm{GPI}\right)$, or apolipoprotein $\mathrm{H}$, was recently attributed anti-angiogenic properties both in vitro and in vivo [15]. These reports add new reasonable $\beta_{2}$ GPI importance on tissue regeneration and tissue proliferation to the already identified complexity of the signaling activities of $\beta_{2}$ GPI upon haemostasia and inflammation.

The plasma protein $\beta_{2}$ GPI was first reported in 1961 [6] as a protein from the beta-globulin fraction of plasma. $\beta_{2}$ GPI is single a polypeptide chain of 326 aminoacids organized in five domains bearing 11 disulfide bridges, and 5 asparagine glicosylation sites [7]. Plasma concentrations between $142 \pm 30$ and $271 \pm 122 \mu \mathrm{g} / \mathrm{ml}$ were reported for healthy individuals, measured through ELISA tests by several research groups [8-12]. In plasma around $60 \%$ of the protein circulates in a free form and $40 \%$ bound to lipoproteins, mainly rich in triglycerides fractions, quilomicrons and VLDL, a minor portion in HDL [13]. The gene responsible for $\beta_{2}$ GPI transcription is placed in 17q23-241 chromosome [14,15] and the main site of its synthesis is the liver $[16,17]$. Other synthesis sites are endothelial cells, intestines, trophoblasts and monocytes $[18,19]$. $\beta_{2}$ GPI undergoes renal reabsortion attached to megalin [20].

The $\beta_{2}$ GPI molecule represents a multifunctional endothelial cell ligand, accessible for systemic and local autocrine and paracrine signaling. In vivo $\beta_{2}$ GPI molecules are immobilized by binding to heparan sulfate molecules expressed in the endothelial cell membranes, but $\beta_{2}$ GPI can also bind to the anionic phospholipids enriched membranes of activated and senescent cells, and to functional receptors like ApoER2, annexin A2, TRL (Toll-like receptors) 2 e 4 and proteoglycans [21-24]. The short consensus repeat domains of $\beta_{2}$ GPI are typical of the complement control proteins superfamily (CCP), although the $\mathrm{C} 4$ convertase activity was not documented for this protein [25]. Monomeric as well as dimeric forms can be found after conventional purification, and higher aggregates were observed in nonreductive conditions, by SDS-PAGE [26]. Monomer and dimer differ in their redox abilities and also in the antinflammatory properties. Dimerization is increased after protein severing and oxidation.

Physiological injury-limiting mechanisms are being increasingly implicated in the redox regulation of microcirculation homeostasis, and may interfere with multiple cell functions [27-29]. The $\beta_{2}$ GPI antiaterogenic effects were attributed to the protein reductive faculty to inhibit lipid oxidation in vivo. Dimerization extent is probably low in

*Corresponding author: Ligia Ferreira Gomes, Department of Clinical and Toxicological Analysis, Faculty of Pharmaceutical Sciences University of Sao Paulo, 580, BI 17 S, Lineu Prestes Avenue, 05508-900, Sao Paulo, Brazil, Tel: +55 1130913638; Fax: +55 1138132197; E-mail: Ifgomes@usp.br

Received July 25, 2013; Accepted October 08, 2013; Published October 10 2013

Citation: Machado C, Nicot ME, Stella CN, Vaz S, Prado C, et al. (2013) Digital Image Processing Assessment of the Differential in vitro Antiangiogenic Effects of Dimeric and Monomeric Beta2-Glycoprotein I. J Cytol Histol 4: 187. doi: 10.4172/2157-7099.1000187

Copyright: (c) 2013 Machado C, et al. This is an open-access article distributed under the terms of the Creative Commons Attribution License, which permits unrestricted use, distribution, and reproduction in any medium, provided the original author and source are credited. 
physiologic situations. Patients with isquemic stroke have higher levels of $c \beta_{2}$ GPI than healthy individuals [30]. In disseminated intravascular coagulation, there is a reduction in plasma concentration of $\beta_{2} \mathrm{GPI}$, which suggests the consumption of the protein [8]. In these cases, the proteolytic cleavage of $\beta_{2}$ GPI may not be the only mechanism of clearance, since the reduction in $\beta_{2}$ GPI levels is greater than the increase of $c \beta_{2}$ GPI [10]. Dimers, besides higher order aggregates, and closed conformation protein structures probably account for a further reduction in $\beta_{2}$ GPI plasma levels [31]

The fifth $\beta_{2}$ GPI domain, the relevant modification site within $\beta_{2}$ GPI structure, binds to membrane anionic phospholipids $(\mathrm{Kd}=330 \mathrm{nM})$, DNA and heparin [12,32]. Heparin stimulates cleavage of the fifth $\beta_{2}$ GPI domain by plasmin, producing a redox labile form of the $\beta_{2}$ GPI nicked form (c $\beta_{2}$ GPI) [33]. Thrombin, tPA, tissue factor/ VIIa factor and uroquinase are not capable of cleaving $\beta_{2}$ GPI. The $\beta_{2}$ GPI cleavage by factor $\mathrm{Xa}$, is very slow [34] or not observable [10]. The $c \beta_{2}$ GPI is generated in vivo in pathological states of increased fibrinolysis and is unable to bind phopholipids [10,35,36]. Redox mechanisms were investigated in addition to the enzymatic cleavage [37-39]. Recently, endothelial cells and platelet secretion of thiol oxyreductases were associated to the $\beta_{2}$ GPI reduction $[40,41]$ and to the functional activation of its dependent vascular targets [40,42]. Ioannou et al. [41] reported the increased in vitro survival of endothelial cells acted by reduced $\beta_{2}$ GPI, by using thyorredoxin and NADPH.

Binding of $\beta_{2}$ GPI through the lysine rich portion of domain $\mathrm{V}$ to negatively charged phospholipids on the surface of endothelial cells and its later cross-linkage by anti- $\beta_{2}$ GPI antibodies was described to activate these cells [19].

The self amplification nature of the redox dimerization signaling was hypothesized as the switch event for vascular destabilization and sprouting. Therefore, this work was designed to evaluate the antiangiogenic effects of monomeric and dimeric $\beta_{2}$ GPI, along with their mixture, represented by the purified native protein. The proliferation, migration, and differentiation of endothelial cells were considered in an in vitro angiogenesis model based on 3D cultures and quantitative digital image processing techniques [43]. This approach was considered convenient due to the low protein amount requirements for cell distribution assessment, even if localized effects were to be observed. The morphological aspects were correlated to the cell growth, oxidative balance outcome and mitochondrial toxicity assays.

\section{Materials and Methods}

\section{$\beta_{2}$ - glicoprotein I ( $\beta_{2}$ GPI) purification fractions}

Human $\beta_{2}$ GPI was affinity-purified from long term stored human plasma so as to take advantage of the spontaneous $\beta_{2}$ GPI dimerization. The individual plasma bags from at least three different donors were kept under $-80^{\circ} \mathrm{C}$ for three to five years, defrosted overnight at $4^{\circ} \mathrm{C}$, pooled, and precipitated with perchloric acid $[13,44]$, then centrifugated at $1100 \mathrm{~g}$ for 30 minutes at $4^{\circ} \mathrm{C}$. The supernatant was collected, neutralized to $\mathrm{pH} 7.0$ with saturated sodium carbonate solution, dialyzed twice against ten volumes of distilled water, then against ten volumes of 20 $\mathrm{mM}$ Tris/pH 7.0, $30 \mathrm{mM} \mathrm{NaCl}$ (equilibration buffer) for 24 hours at $4^{\circ} \mathrm{C}$. The affinity chromatography was carried out with a HeparinSepharose column (Heparin Sepharose 6 Fast Flow, GE Healthcare, Sao Paulo). Unspecific bonds were eliminated by flushing the column with Tris $20 \mathrm{mM} 50 \mathrm{mM} \mathrm{NaCl} \mathrm{pH} 7.0$ buffer. The $\beta_{2}$ GPI fractions were then eluted with $20 \mathrm{mM}$ Tris $200 \mathrm{mM} \mathrm{NaCl} \mathrm{pH} 8.0$ buffer and collected in sequential $2 \mathrm{ml}$ fractions. All the chromatographic procedure was performed at $4^{\circ} \mathrm{C}$. After elution, the column was washed with $20 \mathrm{mM}$ Tris $500 \mathrm{mM} \mathrm{NaCl} \mathrm{pH} 8.0$ buffer.

Purification of $\beta_{2}$ GPI by affinity chromatography was monitored by $280 \mathrm{~nm}$ absorbance change (NanoDrop ND-1000, Uniscience, Sao Paulo), SDS-PAGE $12.5 \%$ and immunoblot with the anti-human $\beta_{2}$ GPI specific monoclonal antibodies 5F7 (ICN, Irvine, California) and K22 [45]. The purity and stability of the produced batches were analyzed by SDS-PAGE $12.5 \%$, immunoblotting and indirect enzyme immunoassay (ELISA). Aliquots of eluted protein were classified according to its content on dimer rich or monomer rich purification fractions, kept in a refrigerator at $4^{\circ} \mathrm{C}$. Dimer and monomer rich aliquots were assayed as independent purified fractions or pooled to represent the plasma blend of $\beta_{2}$ GPI moieties and used without further processing. The average yield was $38.7 \pm 15 \mathrm{mg}$ purified $\beta_{2}$ GPI / L of human plasma $(\mathrm{n}=10$ independent purifications, $500 \mathrm{~mL}$ each). Monomer and dimer contents can vary considerably among different donors, but there were considered the situation in which both $\beta_{2}$ GPI fractions produced densitometrically equivalent bands in the SDS-PAGE $12.5 \%$ [45].

\section{HUVEC growth and differentiation studies}

Human umbilical vein endothelial cells (HUVEC, ATCC CRL1730) were obtained from ATCC Rockville MD USA and cultivated in sterile polystyrene six-well plates $1 \times 10^{3}$ cells/well in $1 \mathrm{~mL}$ RPMI 1640 (Invitrogen, São Paulo) pH 7.4 supplemented with $10 \%$ (v/v) fetal calf serum and $1 \%(\mathrm{v} / \mathrm{v})$ antibiotic mixture, under 5\% CO2 atmosphere, $37^{\circ} \mathrm{C}$ and $70 \%$ humidity. Non-toxic $\beta_{2}$ GPI concentrations were tested in 2D HUVEC cultures, the purified protein was added to the culture medium in the $0.2 \mu \mathrm{M}$ to $2 \mu \mathrm{M}$ range. The HUVEC growth and the peroxidative response were evaluated in $24 \mathrm{~h}$ intervals, in a 3 days period. Tubule formation was studied in $3 \mathrm{D}$ cultures grown in sterile polystyrene six-well plates. The experimental procedure consisted in placing a $30 \mu \mathrm{L}_{\text {Matrigel }}{ }^{\circ}$ (BD Biosciences, São Paulo) in the middle area of the well and then dropping around it $1 \mathrm{~mL}$ of a $1 \times 10^{4}$ cells suspension in RPMI $1640 \mathrm{pH} 7.4$ supplemented with $1 \%$ (v/v) antibiotic mixture, under $5 \% \mathrm{CO} 2$ atmosphere, $37^{\circ} \mathrm{C}$ and $70 \%$ humidity. The distinct purification fractions of $\beta_{2}$ GPI were added to the culture medium after cell adhesion in the same concentration $0.2 \mu \mathrm{M}$ and the growth was evaluated after $24 \mathrm{~h}$ culture.

\section{Metiltetrazolium reduction assay for citotoxicity (MTT)}

Cells were cultivated for $24 \mathrm{~h}$ in 96 -well plates, $3 \times 10^{5}$ cells $/$ well in $100 \mu \mathrm{L}$ RPMI $1640 \mathrm{pH} 7.4$ supplemented with $10 \%$ (v/v) fetal calf serum and $1 \%(\mathrm{v} / \mathrm{v})$ antibiotic mixture, under $5 \% \mathrm{CO}_{2}$ atmosphere, $37^{\circ} \mathrm{C}$ and $70 \%$ humidity. Then, medium was replaced and cells were exposed to the distinct purification fractions of $\beta_{2}$ GPI in the same volume of RPMI $1640 \mathrm{pH} 7.4$ supplemented 1\% (v/v) antibiotic mixture for $24 \mathrm{~h}$. Untreated cells were cultivated in the same conditions, only without the protein. Blank reaction controls were run without cells. Next day, the medium was carefully removed and $20 \mu \mathrm{L}$ of a $5 \mathrm{mg} / \mathrm{ml}$ MTT solution was added to each well and the plate was horizontally shaken for $3 \mathrm{~h}$, $37^{\circ} \mathrm{C}$. After addition of $150 \mu \mathrm{L}$ of DMSO to each well, the plate was delicately shaken and the $490 \mathrm{~nm}$ absorbance was measured in an ELISA reader, within $10 \mathrm{~min}$.

\section{Thiobarbituric acid assay of in vitro lipid peroxidation (TBARS)}

The lipid peroxidation was measured in the cell cultures supernatants by the classical TBARS procedure [46]. Briefly, $40 \mu \mathrm{L}$ of each supernatant were added in triplicate tubes with $200 \mu \mathrm{L}$ of TBA reagent, $0.86 \%$ thiobarbituric acid. There were also run triplicate tubes 
added with the reagent vehicle, $20 \%$ trichloroacetic acid. The reaction mixtures were kept at $100^{\circ} \mathrm{C}$ for $20 \mathrm{~min}$, centrifuged at $8000 \mathrm{rpm}$ for 4 min in a minifuge equipment and the supernatants absorbances were measured at $535 \mathrm{~nm}$. Lipopoperoxidation was measured as aldehyde formation by the formula:

$$
\text { Total TBARS }=\frac{\left(A_{535 n m, T B A}-A_{535 n m, T C A}\right)}{0,0312} \text { nmolesMDA } / m L
$$

\section{Image capture}

Colored photomicrographies from the cell cultures were captured with a Samsung ES80 camera, in $4000 \times 3000$ pixels resolution in the inverted microscope equipped with a plan achromatic 20x objective.

\section{Image processing}

The Image processing and statistics algorithms were written in the Matlab language. The acquired images were converted to grayscale. These images have the non-homogeneous illumination, which was corrected by an a posteriori automatic background adjustment procedure [47-52]. The background surface was simulated as a Savitzky-Golay iterative procedure [53], appropriate for polynomial interpolation of a data set with smooth variations.

Given $\mathrm{n}+1$ points $(\mathrm{x}, \mathrm{y})$, with $i=0,1, ., n$, it was determined a (n) degree polynomium $\mathrm{y}(\mathrm{x})$, as described by:

$$
y(x)=\sum_{i=0}^{n} a_{i} x^{i}
$$

With the data points, it was build a linear system with $\mathrm{n}+1$ equations and the polynomial coefficients $A=[a 0, \cdots, a n]$ were determined thorough a least square estimation calculus. Then, the illumination was corrected by subtracting the background from the original image. This procedure assume that the input image $I(x, y)$ is formed by a shadow component $S(x, y)$, that corrupts the original image

$$
\begin{aligned}
& U(x, y)[54] . \\
& I(x, y)=S(x, y)+U(x, y)
\end{aligned}
$$

The corrected image $U^{c}(x, y)$, corresponds to an estimate of the original image $U(x, y)$ :

$$
U^{c}(x, y) \cong U(x, y)=I(x, y)-S(x, y)
$$

The corrected images are converted to binary black and white images, applying a threshold obtained by the Otsu method. From the global image data, the threshold value was selected to result in the lower interclass variation among black and white pixels, normalized to the $(0,1)$ interval. The noise level that appear in the image was controlled by a morphology transformation of the opening and closing type. The binary regions of the resulting image were labeled and the contours of this were obtained [55]. There were calculated the mean density, mean area, elongation coefficient and circularity of each region, as described below.

- Mean region area

MRA $=\frac{\sum_{i=1}^{n_{\text {reg }}} A_{\text {reg }}}{A_{T}} \times 100$

Where

$n_{-}$reg : Number of labeled regions

$A_{\text {reg }}$ : Area of the labeled region

$A_{T}$ : Total image area

- $\quad$ Mean region density

$M R D=\frac{n_{-} \text {reg }}{A_{T}} \times 100$

$$
\begin{aligned}
& \text { - } \quad \text { Circularity coefficient } \\
& C C=\frac{4 \pi A_{\text {reg }}}{p_{\text {reg }}^{2}} \\
& \text { Where } \\
& p_{\text {reg }}: \text { Perimeter of the labeled region } \\
& \text { - } \quad \text { Elongation coefficient } \\
& E C=\frac{M i A_{\text {reg }}}{M a A_{\text {reg }}}
\end{aligned}
$$

The structures HUVEC formed in the 3D culture substrates after $24 \mathrm{~h}$ growth were automatically measured and classified. The region morphologies were classified as circular, elongated or deformed according to the relationships among their elongation and circularity coefficients. The elongation coefficient $<0.5$ was the classification criterion for elongated regions, while regions with elongation coefficient $>0.5$ were considered circular if their circularity coefficient $>0.8$. The regions with elongation coefficient $>0.5$ and circularity coefficient $<0.8$ were classified as deformed. Same procedure was applied to the $2 \mathrm{D}$ cultures, after 24 and $72 \mathrm{~h}$ growth.

\section{Statistics}

The groups were compared through two way ANOVA followed by Tukey test of the means, significance levels were set to $95 \%$.

\section{Results}

\section{HUVEC growth and differentiation}

$\beta_{2}$ GPI was largely nontoxic to the cultures in the tested concentrations. A concentration dependent $24 \mathrm{~h}$ lag was observed in the cell proliferation, as reported by cell counting results. This growth interruption occurred without modification of the mitochondrial function as measured by the MTT reduction assay (Figure 1). Despite TBARs evaluation of lipid peroxide production were equivalent after 24h between $\beta_{2}$ GPI treated and untreated HUVECs (Figure 1), lipid peroxidation products increasingly accumulated in the HUVEC cultures treated with $\beta_{2}$ GPI after $48 \mathrm{~h}$ and $72 \mathrm{~h}$, in comparison with untreated cultures. Altogether, results were ascribed to stabilization signaling by $\beta_{2}$ GPI upon non-confluent HUVEC cultures, which however remained competent to proliferate.

\section{Image processing}

Each obtained photomicrography processing resulted in a set of sequentially modified images, as exemplified in Figure 2 . The original image (Figure 2A) was first converted to the grayscale image (Figure $2 \mathrm{~B}$ ), then to the corrected background image (Figure 2C) and finally to the binary image (Figure 2D). The binary images were employed to calculate the model parameters for the 3D HUVEC cultures. The results are shown in Table 1.

\begin{tabular}{|l|c|c|c|c|c|}
\hline & $\begin{array}{c}\text { Mean region } \\
\text { area values, \% }\end{array}$ & $\begin{array}{c}\text { Mean region } \\
\text { density } \\
\text { values, (pixel)-2 }\end{array}$ & $\begin{array}{c}\text { Circularity } \\
\text { coefficient }\end{array}$ & $\begin{array}{c}\text { Elongation } \\
\text { coefficient }\end{array}$ & $\begin{array}{c}\text { Other, } \\
\text { deformed }\end{array}$ \\
\hline Untreated & 20.0701 & 0.0069 & 246 & 253 & 334 \\
\hline Dimer & 22.2827 & 0.0066 & 242 & 115 & 443 \\
\hline Monomer & 14.7786 & 0.0036 & 96 & 100 & 247 \\
\hline Pool & 17.3205 & 0.0062 & 152 & 158 & 424 \\
\hline
\end{tabular}

aHUVEC cultures were initiated with $10^{4}$ cells and treated with purified $\beta_{2}$ GPI and its purification fractions in the final concentration of $0.2 \mu \mathrm{M}$. Dilution buffer was employed in the untreated cultures as a control. Results from a typical assay. Table 1: Experimental angiogenesis quantification results in 3D HUVEC cultures ${ }^{\text {a }}$. 
Citation: Machado C, Nicot ME, Stella CN, Vaz S, Prado C, et al. (2013) Digital Image Processing Assessment of the Differential in vitro Antiangiogenic Effects of Dimeric and Monomeric Beta2-Glycoprotein I. J Cytol Histol 4: 187. doi: 10.4172/2157-7099.1000187
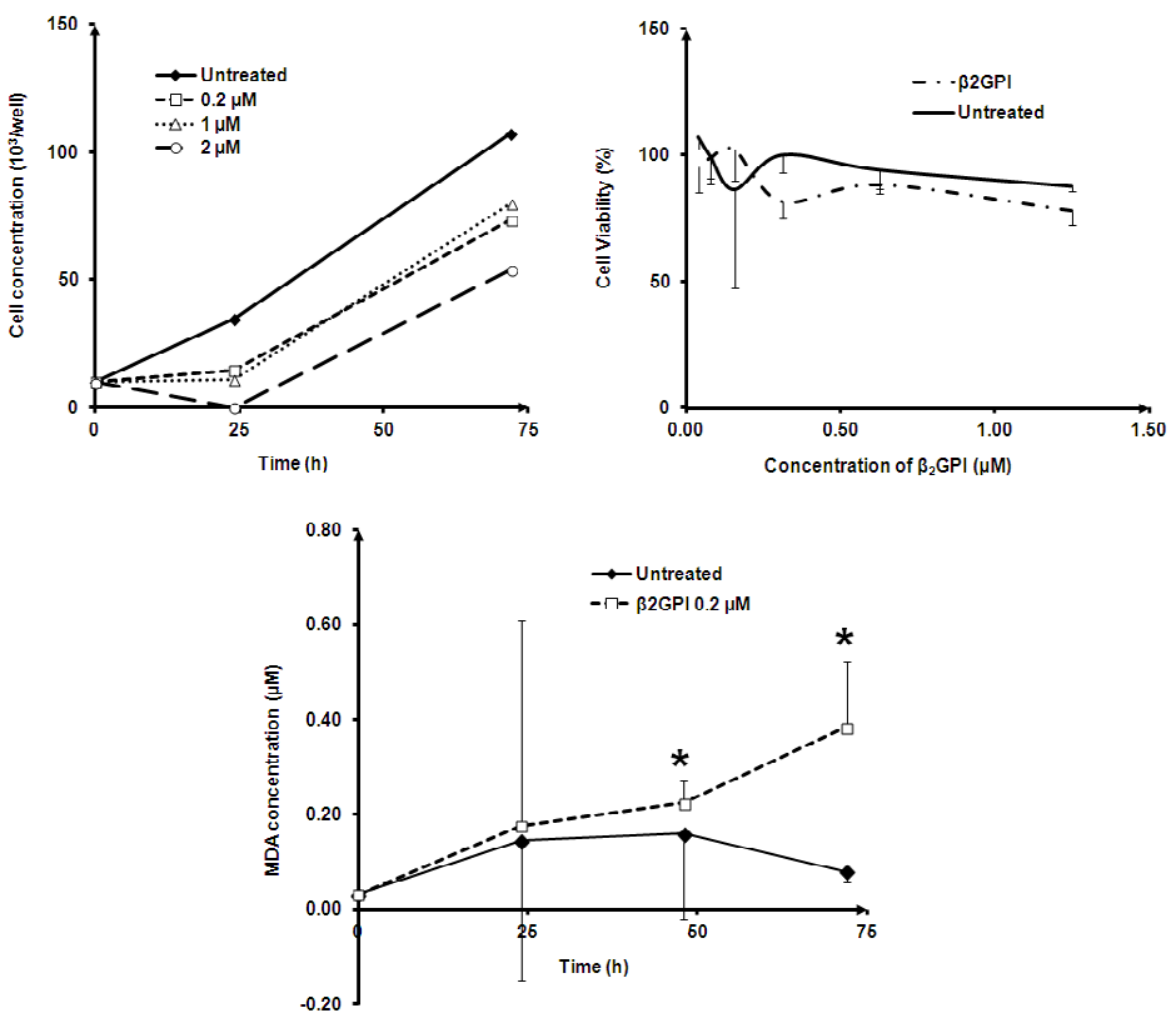

Figure 1: Purified $\beta_{2}$ GPI concentration effect upon of cell growth and differentiation. (A) HUVEC growth in 6 -well NUNC plates, initial cell concentration 10 ${ }^{3}$ cells/mL; (B) mitochondrial activity in the MTT reduction test, and (C) Peroxidative activity as TBARS concentration in the HUVEC cultures supernatants in the presence of purified $\beta_{2}$ GPI $0.2 \mu \mathrm{M}$. The asterisks indicate the significant differences between treated and untreated groups.
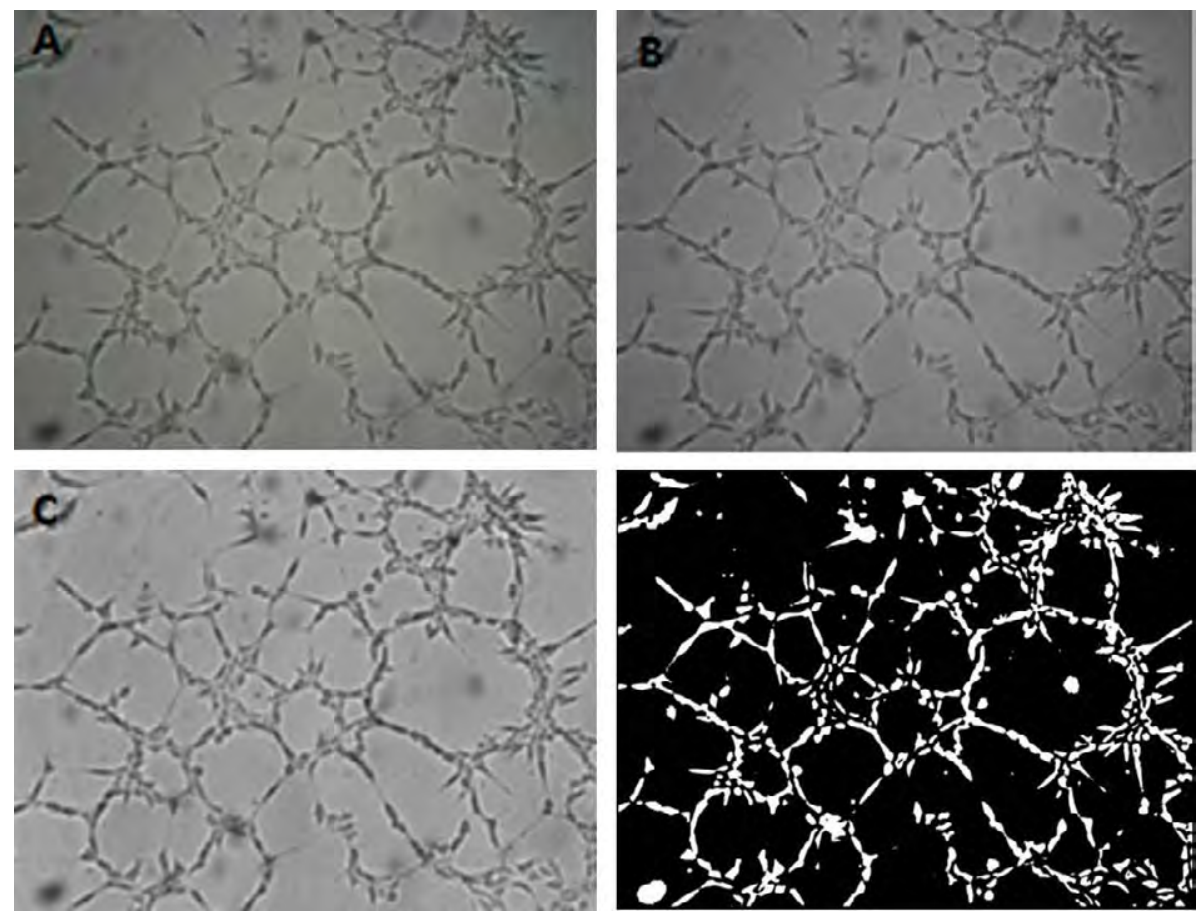

Figure 2: Image processing steps results. The original image ( Figure: $2 \mathrm{~A}$ ) was first converted to the grayscale image ( Figure: $2 \mathrm{~B}$ ), then submitted to a $2^{\text {nd }}$ degree polinomial background correction ( Figure: $2 \mathrm{C}$ ) and finally to the umbralization algorithm, to obtain the binary image ( Figure: 2D). 
Citation: Machado C, Nicot ME, Stella CN, Vaz S, Prado C, et al. (2013) Digital Image Processing Assessment of the Differential in vitro Antiangiogenic Effects of Dimeric and Monomeric Beta2-Glycoprotein I. J Cytol Histol 4: 187. doi: 10.4172/2157-7099.1000187

\section{Discussion}

A differential anti-angiogenic effect of purified $\beta_{2}$ GPI monomer and dimer rich fractions was demonstrated. The morphological evaluation was correlated to the biochemistry assay, leading to the evidence that non-confluent HUVEC cultures temporarily stop growing in the presence of the native protein, while they remain competent to proliferate (Figure 1). Purified $\beta_{2}$ GPI was recently attributed antiangiogenic properties both in vitro and in vivo [1-5]. These reports added new reasonable $\beta_{2}$ GPI importance on tissue regeneration and tissue proliferation to the already identified complexity of the signaling activities of $\beta_{2}$ GPI upon haemostasia and inflammation.

Chiu et al. [56,57] reported an inhibitory effect of $\beta_{2}$ GPI upon human aortic endothelial cells migration in vitro, without affecting cell proliferation and survival. They couldn't attribute the observed effects to the $\beta_{2}$ GPI purification fractions. The biochemical evidence on the mitochondrial functionality is in accordance with the effects observed by Chiu and collaborators (Figure 1). The viability and growth profile of the unexposed HUVEC cultures and the effect of native $\beta_{2}$ GPI upon the cells agree well with the literature. Even though mitochondrial toxicity was not produced by $\beta_{2}$ GPI in the $0.2 \mu \mathrm{M}$ to $2 \mu \mathrm{M}$ range (Figure 1 ), it was observed a delay in the cell proliferation and an increase in lipoperoxide production after $48 \mathrm{~h}$ and $72 \mathrm{~h}$ in the presence of the purified protein at $0.2 \mu \mathrm{M}$ concentration (Figure 1). Comparable concentrations of $\beta_{2}$ GPI were previously observed to modify ex-vivo liver uptake of colloidal carbon particles [58].

HUVEC proliferation and migration was feebly sensitive to native $\beta_{2}$ GPI monomer. The morphological approach allowed to unequivocally attributing the inhibition of tube organization by the $\beta_{2}$ GPI dimer (Figure 3 ). The $\beta_{2}$ GPI dimerization, and further molecule-molecule association is determined by concentration and surface association is reversible [45]. It can be fixed by subsequent linkage of enzymatically or oxidatively nicked protein molecules by the initial biochemical pathways of the regenerative cascade at vascular wall, producing an autocrine signaling looping for antiangiogenesis [5,22].

The conventional morphological analysis of the in vitro HUVEC growth and differentiation, which simulates the vessel sprouting mechanism of angiogenesis in the tridimensional cultures microenvironment, was applied to the study of the early steps of tube formation. The in vitro modeling of the angiogenesis related phenomena of cell growth and differentiation into tubular structures was feasible after background correction (Figure 2). The conventional counting of the number and node regions of the trabeculae formed in the measured field was substituted by individual cell functional descriptors. There were considered the mean area and number densities of the individual regions produced in the binary images, as well as its morphology. The mean region area stands for the increase in the cell numbers in the field, while the mean region density combines the cell number increase with the cell to cell bridge formation, a differentiation event. Cell size modification and formats interferes with both parameters, and then they were always analyzed as a profile, rather than an independent representation of the cellular behavior. The time distribution of the region formats counts revealed the differential increase of elongated and deformed regions, corresponding to the several cell to cell interactions arranges which contribute to the trabeculae formation. Circular regions were kept in lower numbers and probably correspond to the proliferative and degenerative fraction of cellular elements in the observation field. Elongation received special attention, because elongation precedes the successful trabeculae formation. Circular regions were associated with proliferative behavior
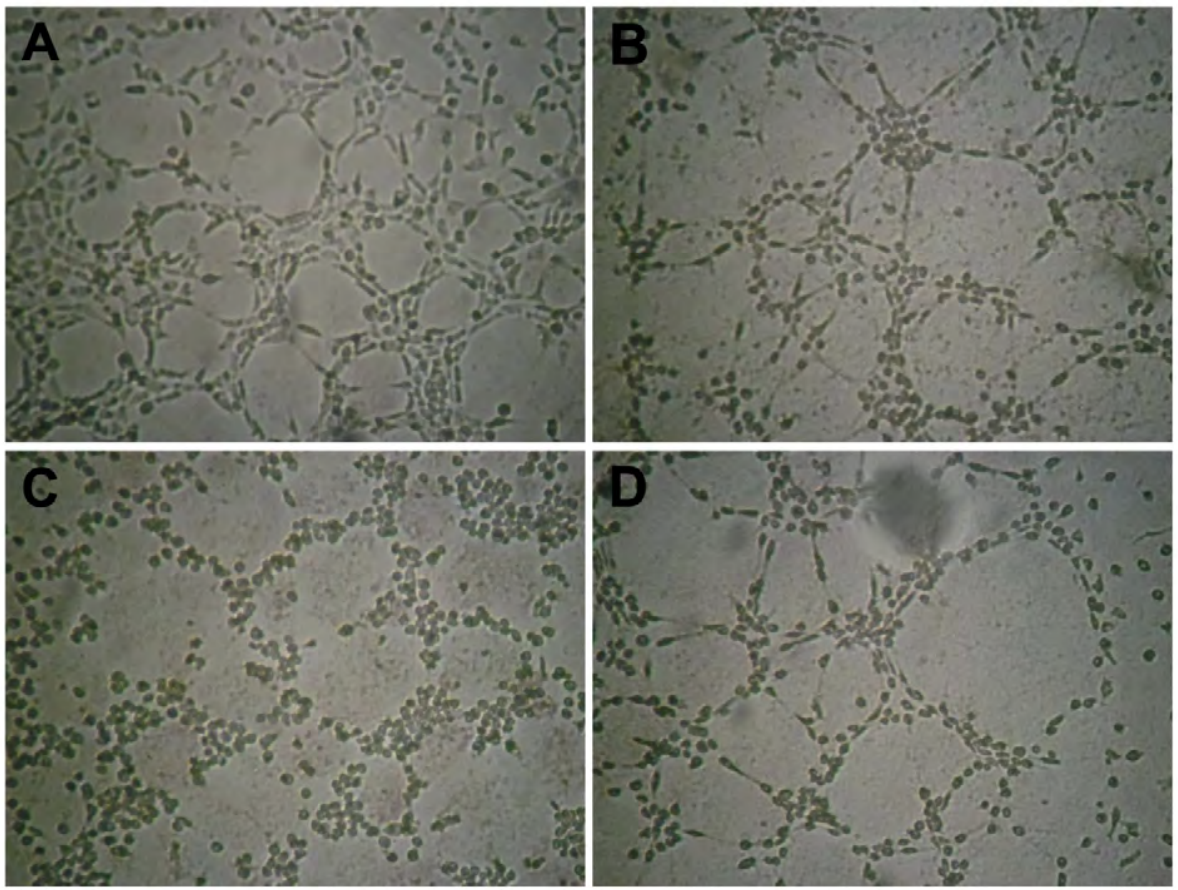

Figure 3: Typical morphology of 3D HUVEC cultures. Untreated (A), or in the presence of purified $\beta_{2}$ GPI (B) and the (C) Dimer; and (D) Monomer subfractions. Cultures were initiated with $1 \times 10^{4}$ cells seeded in $1 \mathrm{~mL}$ RPMI 1640 medium supplemented with an antibiotic mixture around a $30 \mu \mathrm{L}$ Matrigel $\Omega^{\circ}$ button, as described under materials and methods section. The $\beta 2 \mathrm{GPI}$ moieties $(0.2 \mu \mathrm{M})$ were added into medium after cell adhesion and the growth was evaluated after $24 \mathrm{~h}$ culture. Photomicrographies were taken in an inverted microscope under 10x magnification. 
Other shapes were referred to completed trabeculae, superimposed cell regions, and probably also non identifiable fragments and cell debris. Number increases of all parameters were indicative of cell proliferation, while the proportions could be employed to analyze cell migration and differentiation.

The protein exposure could be associated with mean region area values equivalent to those obtained for the unexposed HUVEC cultures in the cultivation time tested, but the dimer and monomer fractions behaved slightly different. Dimer and monomer rich fractions presented very divergent aspects in the 3D cultures, both for the area and density parameters and for the distribution of the selected region format counts (Figure 3 and Table 1). In the first 24h, the HUVEC cultures exposed to purified protein pool reached mean region area values equivalent to those observed in unexposed conditions. Equivalent values were obtained for the dimer rich fraction, while the monomer rich fraction induced 35\% lower values. The mean region densities were higher in the cultures exposed to the dimer rich than those obtained after exposure to the monomer rich fractions; while the purified pool exposure were associated to region density values close to those promoted by the dimer rich fraction. Taken together with the region format counts, it seems reasonable to associate the higher cell expansions with the dimer rich fractions. Circular regions represent either the proliferative and senescent cell morphology, while elongated regions derive from cell migration and distribution in the trabecular structures, rather corresponding to cell differentiation and sprout stabilization. True trabeculae correspond ideally to only one region, because of the close proximity of the cell membranes and the interdigitating structures within their interfaces, which are not discriminable in the binary images. Noteworthy, the pool apparently resulted in a nonhomogeneous distribution of the cells in a pattern composed by morphological domains of both types (Figure 3).

The 3D cultures shown in Figure 3 and Table 1 well demonstrate how the morphological evidence could help to describe the complexity of the outcome possibilities for biological systems in which there putatively coexist biochemical conversion of bioactive molecules and emergence of interdependent effects. The selected parameters were suited to differentially demonstrate the proliferative and maturative components of the trabeculae formation.

The focal proliferation association with the migration inhibition constrained the proportions of the considered parameters, and then the resultant tube loss could be discriminated from pure nonproliferative or survival inhibition effects (Table 1). Endothelial cell activation and death were previously ascribed to dimeric and nicked protein forms [45]. The $\beta_{2}$ GPI monomer and dimer were previously reported to differentially modify platelet activation [22,23,59]. Native $\beta_{2}$ GPI inhibits the respiratory burst of resident macrophages [44] and also the foam cell formation [60]. Physiologically, this later phenomenon was related to lipid-carrier proteins intake $[61,62]$. Both platelet and leukocyte activation are essentially dependent on surface characteristics and there may occur topographical signaling by $\beta_{2}$ GPI structures, an underexplored source of biological effects. The morphological approach, and the assay of $\beta_{2}$ GPI solutions enriched with either monomer or dimer fractions was mostly useful to reveal the motility interference pathogenesis of the paradoxical association of increased cell growth and diminished sprouting associated to the protein and to specifically attribute this antiangiogenic activity to the $\beta_{2}$ GPI dimerization, while dimeric and monomeric forms apparently associated with opposite effects. Despite vascular tree architecture and dynamic organization should be sensitive to the protein monomer, an extensive early antiangiogenic outcome by excess $\beta_{2}$ GPI monomer is indeed not expected to occur, because both lower proliferation and preserved elongation are essentially self-limited in time by $\beta_{2}$ GPI consumption and dimerization [63]. The cell migration resulted less susceptible to the dimeric fraction, even though viability and growth were preserved. This work demonstrated that cross-linked dimeric protein is able to perform the whole endothelial cell activation, without the requirement of the anti- $\beta_{2}$ GPI antibodies.

The morphological modeling of 3D cultures then allowed identifying dimerization interference for the inhibition of the endothelial cell migration by $\beta_{2}$ GPI, an antiangiogenic and self-limited in vitro effect of the protein monomer that precedes the peroxidative response associated with the untied cell proliferation in endothelial cell cultures.

\section{Conclusions}

Purified $\beta_{2}$ GPI preserved HUVEC mitochondrial viability in vitro, but cell proliferation was reduced or arrested during the first $24 \mathrm{~h}$. This lag-inducing effect was not concentration-dependent in the $0.2 \mu \mathrm{M}$ to $2 \mu \mathrm{M}$ range. Peroxidation was not increased before $72 \mathrm{~h}$ in culture treated with $0.2 \mu \mathrm{M} \beta_{2}$ GPI. There were observed a differential effect of monomer and dimer rich $\beta_{2}$ GPI purification fractions upon the cell cultures. The native $\beta_{2}$ GPI monomer allowed the in vitro differentiation of the HUVECs into typical trabeculae and incomplete capillary-like tubes, but reduced apparent cell densities. In opposition, the dimer rich fraction exposure halted cell elongation and migration, and prevented the organization of the tubular structures in $3 \mathrm{D}$ cultures, without disrupting cell proliferation. The pooled fractions were able to both proliferate and organize tubular structures.

The morphological approach was useful to attribute to the in situ $\beta_{2}$ GPI dimerization the recovery of untied cell proliferation in endothelial cell cultures and the overcome of the diminished sprouting antiangiogenic effect of the monomer fraction of the native protein.

\section{Acknowledgements}

This work received financial support from National Research Council (CNPq) regular project protocol number 474654/2004-4 and from São Paulo Research Foundation (FAPESP), protocol number 2007/57728-5. Sara Vaz was in receipt of a Santander Mobility Fellowship for undergraduate student. Prof. Francisco Palacios Fernández and Prof. Miriela Escobedo Nicot were in receipt of Mobility and Ph.D. Fellowships from Brazilian Government under the Education Department CAPES/ MES Brazil-Cuba Cooperation Program. The Blood Bank of the Public Servants Hospital of the State of São Paulo (HSPE-IAMSPE) furnished the human plasma used in this work.

\section{References}

1. Rakic JM, Maillard C, Jost M, Bajou K, Masson V, et al. (2003) Role of plasminogen activator-plasmin system in tumor angiogenesis. Cell Mol Life Sci 60: 463-473.

2. Beecken WD, Engl T, Ringel EM, Camphausen K, Michaelis M, et al. (2006) An endogenous inhibitor of angiogenesis derived from a transitional cell carcinoma: clipped beta2-glycoprotein-I. Ann Surg Oncol 13: 1241-1251.

3. Sakai T, Balasubramanian K, Maiti S, Halder JB, Schroit AJ (2007) Plasmincleaved beta-2-glycoprotein 1 is an inhibitor of angiogenesis. Am J Pathol 171: 1659-1669.

4. Yu P, Passam FH, Yu DM, Denyer G, Krilis SA (2008) Beta2-glycoprotein inhibits vascular endothelial growth factor and basic fibroblast growth factor induced angiogenesis through its amino terminal domain. J Thromb Haemost 6: 1215-1223.

5. Nakagawa H, Yasuda S, Matsuura E, Kobayashi K, leko M, et al. (2009) Nicked \{beta\}2-glycoprotein I binds angiostatin 4.5 (plasminogen kringle 1-5) and attenuates its antiangiogenic property. Blood 114: 2553-2559. 
Citation: Machado C, Nicot ME, Stella CN, Vaz S, Prado C, et al. (2013) Digital Image Processing Assessment of the Differential in vitro Antiangiogenic Effects of Dimeric and Monomeric Beta2-Glycoprotein I. J Cytol Histol 4: 187. doi: 10.4172/2157-7099.1000187

Page 7 of 8

6. Schultze HE, Heide H, Haupt H (1961) Uber ein Bisher Unbekanntes Niedermolekulares globulin des Humanserums. Naturwissenschaften 48:719 723

7. Lozier J, Takahashi N, Putnam FW (1984) Complete amino acid sequence of human plasma beta 2-glycoprotein I. Proc Natl Acad Sci U S A 81: 3640-3644.

8. Brighton TA, Hogg PJ, Dai YP, Murray BH, Chong BH, et al. (1996) Beta 2-glycoprotein I in thrombosis: evidence for a role as a natural anticoagulant. Br J Haematol 93: 185-194.

9. Balasubramanian K, Killion JJ, Schroit AJ (1998) Estimation of plasma beta-2glycoprotein levels by competitive ELISA. Thromb Res 92: 91-97.

10. Horbach DA, van Oort E, Tempelman MJ, Derksen RH, de Groot PG (1998) The prevalence of a non-phospholipid-binding form of beta2-glycoprotein I in human plasma--consequences for the development of anti-beta2-glycoprotein I antibodies. Thromb Haemost 80: 791-797.

11. Biasiolo A, Rampazzo P, Brocco T, Barbero F, Rosato A, et al. (1999) [Antibeta2 glycoprotein I-beta2 glycoprotein I] immune complexes in patients with antiphospholipid syndrome and other autoimmune diseases. Lupus 8: 121-126.

12. Yasuda S, Tsutsumi A, Chiba H, Yanai H, Miyoshi Y, et al. (2000) beta(2)glycoprotein I deficiency: prevalence, genetic background and effects on plasma lipoprotein metabolism and hemostasis. Atherosclerosis 152: 337-346.

13. Polz E, Wurm H, Kostner GM (1980) Investigations on beta 2-glycoprotein-I in the rat: isolation from serum and demonstration in lipoprotein density fractions. Int J Biochem 11: 265-270.

14. Steinkasserer A, Cockburn DJ, Black DM, Boyd Y, Solomon E, et al. (1992) Assignment of apolipoprotein $\mathrm{H}(\mathrm{APOH}$ : beta-2-glycoprotein I) to human chromosome 17q23----qter; determination of the major expression site. Cytogenet Cell Genet 60: 31-33.

15. Wang $\mathrm{HH}$, Chiang AN (2004) Cloning and characterization of the human beta2-glycoprotein I (beta2-GPI) gene promoter: roles of the atypical TATA box and hepatic nuclear factor-1alpha in regulating beta2-GPI promoter activity. Biochem J 380: 455-463.

16. Steinkasserer A, Estaller C, Weiss EH, Sim RB, Day AJ (1991) Complete nucleotide and deduced amino acid sequence of human beta 2-glycoprotein I. Biochem J 277 : 387-391.

17. Averna M, Paravizzini G, Marino G, Emmanuele G, Cefalù AB, et al. (2004) Beta-2-glycoprotein I is growth regulated and plays a role as survival factor for hepatocytes. Int J Biochem Cell Biol 36: 1297-1305.

18. Conti F, Sorice M, Circella A, Alessandri C, Pittoni V, et al. (2003) Beta-2glycoprotein I expression on monocytes is increased in anti-phospholipid antibody syndrome and correlates with tissue factor expression. Clin Exp Immunol 132: 509-516

19. Meroni PL, Raschi E, Testoni C, Borghi MO (2004) Endothelial cell activation by antiphospholipid antibodies. Clin Immunol 112: 169-174.

20. Moestrup SK, Schousboe I, Jacobsen C, Leheste JR, Christensen El, et al. (1998) beta2-glycoprotein-I (apolipoprotein H) and beta2-glycoprotein-Iphospholipid complex harbor a recognition site for the endocytic receptor megalin. J Clin Invest 102: 902-909.

21. Ma K, Simantov R, Zhang JC, Silverstein R, Hajjar KA, et al. (2000) High affinity binding of beta 2-glycoprotein I to human endothelial cells is mediated by annexin II. J Biol Chem 275: 15541-15548.

22. Lutters BC, Derksen RH, Tekelenburg WL, Lenting PJ, Arnout J, et al. (2003) Dimers of beta 2-glycoprotein I increase platelet deposition to collagen via interaction with phospholipids and the apolipoprotein E receptor 2'. J Biol Chem 278: 33831-33838.

23. Pennings $M T$, van Lummel $M$, Derksen $R H$, Urbanus $R T$, Romijn RA, et al. (2006) Interaction of beta2-glycoprotein I with members of the low density lipoprotein receptor family. J Thromb Haemost 4: 1680-1690.

24. Alard JE, Gaillard F, Daridon C, Shoenfeld Y, Jamin C, et al. (2010) TLR2 is one of the endothelial receptors for beta 2-glycoprotein I. J Immunol 185: 15501557.

25. Ichinose A, Bottenus RE, Davie EW (1990) Structure of transglutaminases. J Biol Chem 265: 13411-13414.

26. Dupuy D'Angeac A, Stefas I, Graafland H, De Lamotte F, Rucheton M, et al. (2006) Biotinylation of glycan chains in beta2 glycoprotein I induces dimerization of the molecule and its detection by the human autoimmune anti-cardiolipin antibody EY2C9. Biochem J 393: 117-127.

27. Stamler JS, Jia L, Eu JP, McMahon TJ, Demchenko IT, et al. (1997) Blood flow regulation by S-nitrosohemoglobin in the physiological oxygen gradient. Science 276: 2034-2037.

28. Lichtman SN, Lemasters JJ (1999) Role of cytokines and cytokine-producing cells in reperfusion injury to the liver. Semin Liver Dis 19: 171-187.

29. Marshall HE, Stamler JS (2002) Nitrosative stress-induced apoptosis through inhibition of NF-kappa B. J Biol Chem 277: 34223-34228.

30. Yasuda S, Atsumi T, leko M, Matsuura E, Kobayashi K, et al. (2004) Nicked beta2-glycoprotein I: a marker of cerebral infarct and a novel role in the negative feedback pathway of extrinsic fibrinolysis. Blood 103: 3766-3772.

31. Agar C, van Os GM, Mörgelin M, Sprenger RR, Marquart JA, et al. (2010) Beta2glycoprotein I can exist in 2 conformations: implications for our understanding of the antiphospholipid syndrome. Blood 116: 1336-1343.

32. Sheng Y, Sali A, Herzog H, Lahnstein J, Krilis SA (1996) Site-directed mutagenesis of recombinant human beta 2-glycoprotein I identifies a cluster of lysine residues that are critical for phospholipid binding and anti-cardiolipin antibody activity. J Immunol 157: 3744-3751.

33. Hunt JE, Simpson RJ, Krilis SA (1993) Identification of a region of beta 2-glycoprotein I critical for lipid binding and anti-cardiolipin antibody cofactor activity. Proc Natl Acad Sci U S A 90: 2141-2145.

34. Hagihara Y, Enjyoji K, Omasa T, Katakura Y, Suga K, et al. (1997) Structure and function of the recombinant fifth domain of human beta 2-glycoprotein I: effects of specific cleavage between Lys77 and Thr78. J Biochem 121: 128-137.

35. Miyakis S, Giannakopoulos B, Krilis SA (2004) Beta 2 glycoprotein l--function in health and disease. Thromb Res 114: 335-346.

36. Ohkura N, Hagihara Y, Yoshimura T, Goto Y, Kato H (1998) Plasmin can reduce the function of human beta2 glycoprotein I by cleaving domain $\mathrm{V}$ into a nicked form. Blood 91: 4173-4179.

37. Arvieux J, Regnault V, Hachulla E, Darnige L, Berthou F, et al. (2001) Oxidation of beta2-glycoprotein I (beta2GPI) by the hydroxyl radical alters phospholipid binding and modulates recognition by anti-beta2GPI autoantibodies. Thromb Haemost 86: 1070-1076.

38. Buttari B, Profumo E, Mattei V, Siracusano A, Ortona E, et al. (2005) Oxidized beta2-glycoprotein I induces human dendritic cell maturation and promotes a $T$ helper type 1 response. Blood 106: 3880-3887.

39. Rahgozar S (2012) Revisiting Beta 2 glycoprotein I, the major autoantigen in the antiphospholipid syndrome. Iran J Immunol 9: 73-85.

40. Passam FH, Rahgozar S, Qi M, Raftery MJ, Wong JW, et al. (2010) Beta 2 glycoprotein I is a substrate of thiol oxidoreductases. Blood 116: 1995-1997.

41. loannou Y, Zhang JY, Passam FH, Rahgozar S, Qi JC, et al. (2010) Naturally occurring free thiols within beta 2-glycoprotein I in vivo: nitrosylation, redox modification by endothelial cells, and regulation of oxidative stress-induced cell injury. Blood 116: 1961-1970.

42. Giannakopoulos B, Mirarabshahi P, Krilis SA (2011) New insights into the biology and pathobiology of beta2-glycoprotein I. Curr Rheumatol Rep 13: 9095.

43. Donovan D, Brown NJ, Bishop ET, Lewis CE (2001) Comparison of three in vitro human 'angiogenesis' assays with capillaries formed in vivo. Angiogenesis 4: 113-121.

44. Gomes LF, Gonçalves LM, Fonseca FL, Celli CM, Videla LA, et al. (2002) beta 2-glycoprotein I (apolipoprotein $\mathrm{H}$ ) modulates uptake and endocytosis associated chemiluminescence in rat Kupffer cells. Free Radic Res 36: 741 747.

45. Stella CN, Gomes LF (2013) Monoclonal antibodies anti-beta2-glycoprotein I: production, characterization, analytical applications. Lambert Academic Publishing, Saarbrücken. ISBN: 978-3-659- 39385-3

46. Draper HH, Hadley M (1990) Malondialdehyde determination as index of lipid peroxidation. Methods Enzymol 186: 421-431.

47. Tomazevic D, Likar B, Pernus $F$ (2002) Comparative evaluation of retrospective shading correction methods. J Microsc 208: 212-223.

48. Russ J (1995) The Image Processing Handbook, 2nd edn. IEEE Press, Boca Raton, Florida. 
Citation: Machado C, Nicot ME, Stella CN, Vaz S, Prado C, et al. (2013) Digital Image Processing Assessment of the Differential in vitro Antiangiogenic Effects of Dimeric and Monomeric Beta2-Glycoprotein I. J Cytol Histol 4: 187. doi: 10.4172/2157-7099.1000187

49. Young I, Gerbrands J, Vliet L (1998) Image Processing Fundamentals. The Digital Signal Processing Handbook. CRC Press, Boca Raton, Florida. 51.151.81

50. Likar B, Viergever MA, Pernus F (2001) Retrospective correction of MR intensity inhomogeneity by information minimization. IEEE Trans Med Imaging 20: $1398-1410$

51. Hou Z, Huang S, Hu Q, Nowinski WL (2006) A fast and automatic method to correct intensity inhomogeneity in MR brain images. Med Image Comput Comput Assist Interv 9: 324-331.

52. Tomazevic D, Likar B, Pernus F (2000) A comparison of retrospective shading correction techniques. Proceedings. 15th International Conference on Pattern Recognition 3: 564-567.

53. Lawrence H. Staib (1998) The image processing handbook, 2nd edition J. C. Russ. Journal of Nuclear Cardiology 5: 451-452.

54. Reyes-Aldasoro, Constantino C (2009) Retrospective shading correction algorithm based on signal envelope estimation. Electronics Letters 45: 454 456.

55. Escobedo M, Ticlia L, Palacios F, Vanconcelos I, Ferreira L, (2013) et al., (2013) Corrección de la iluminación en imágenes de la membrana corioalantoica (CAM) de embriones de gallina. Informatica. ISBN: 978-959-7213-02-4.

56. Chiu WC, Chiou TJ, Chiang AN (2012) Î̃â,,-Glycoprotein I inhibits endothelial cell migration through the nuclear factor $\hat{l}^{\circ} \mathrm{B}$ signalling pathway and endothelial nitric oxide synthase activation. Biochem J 445: 125-133.
57. Chiu WC, Lin JY, Lee TS, You LR, Chiang AN (2013) îª̂,,-glycoprotein I inhibits VEGF-induced endothelial cell growth and migration via suppressing phosphorylation of VEGFR2, ERK1/2, and Akt. Mol Cell Biochem 372: 9-15.

58. Gomes LF, Knox PR, Simon-Giavarotti KA, Junqueira VB, Sans J, et al. (2004) Beta2-glycoprotein I inhibition of mouse Kupffer cells respiratory burst depends on liver architecture. Comp Hepatol 3 Suppl 1: S43.

59. Urbanus RT, Pennings MT, Derksen RH, de Groot PG (2008) Platelet activation by dimeric beta2-glycoprotein I requires signaling via both glycoprotein Ibalpha and apolipoprotein E receptor 2'. J Thromb Haemost 6: 1405-1412.

60. Lin KY, Pan JP, Yang DL, Huang KT, Chang MS, et al. (2001) Evidence for inhibition of low density lipoprotein oxidation and cholesterol accumulation by apolipoprotein H (beta2-glycoprotein I). Life Sci 69: 707-719.

61. Cocca BA, Seal SN, D'Agnillo P, Mueller YM, Katsikis PD, et al. (2001) Structura basis for autoantibody recognition of phosphatidylserine-beta 2 glycoprotein I and apoptotic cells. Proc Natl Acad Sci U S A 98: 13826-13831.

62. Del Papa N, Sheng YH, Raschi E, Kandiah DA, Tincani A, et al. (1998) Human beta 2-glycoprotein I binds to endothelial cells through a cluster of lysine residues that are critical for anionic phospholipid binding and offers epitopes for anti-beta 2-glycoprotein I antibodies. J Immunol 160: 5572-5578.

63. Guidolin D, Albertin G, Ribatti D (2010) Exploring in vitro angiogenesis by image analysis and mathematical modeling. In Méndez-Vilaz A, Díaz J. Eds Microscopy: Science, Technology, Applications and Education. Badajoz, Formatex Microscopy Series 4: 876-884. 